\title{
LEGALISE IT...?
}

The topic of drug reformation is a contentious one due to traditional political and societal views; however, drug reformation is needed. The Misuse of Drugs Act 1971 is outdated and needs to reform to keep up with our ever changing societal values.

The UK should be more like:

\section{Switzerland:}

Switzerland is one of the countries that pioneered the idea of introducing a policy aimed at health rather than criminal justice.

The federal government introduced an open and interlinked four pillar model.

$$
\text { del. }
$$

been

his model has been described as progressive, innovative and effective by experts in the field.

\section{Portugal:
Portugal decriminalised the personal possession of all drugs in 2001. \\ This reform came mainly from a health issue.}

A well-funded commission was established to tackle the issues that would arise from the decriminalisation of all drugs known as the commissions for the dissuasion of drug addiction.

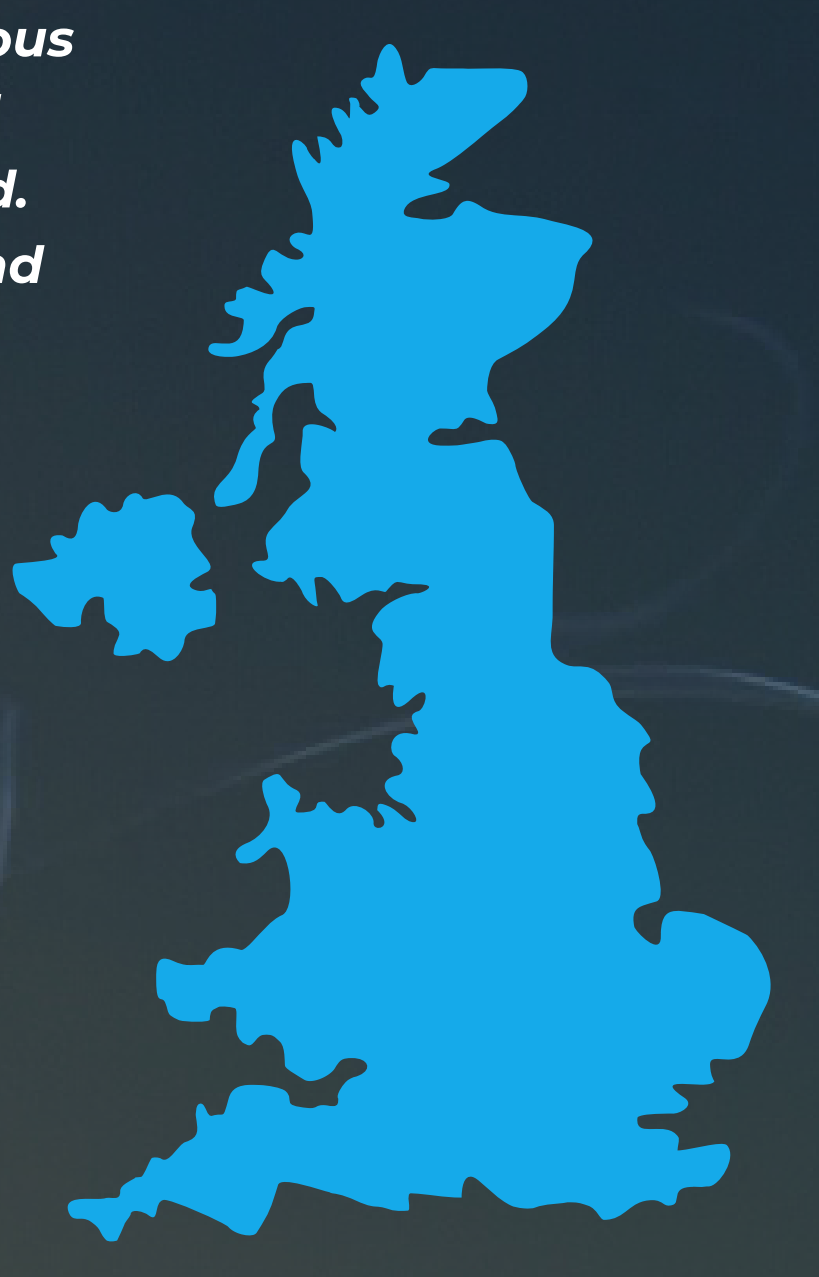

The Law at the Moment:

-Misuse of Drugs Act 1971

-Modern Slavery Act 2015

\section{$59 \%$}

Support legalisation of cannabis 1

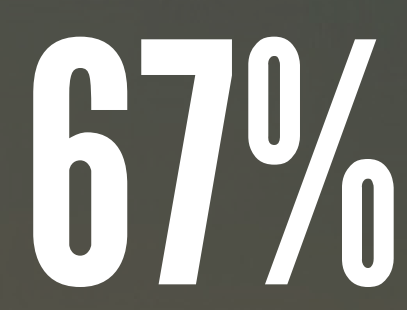

Want a review of Britain's approach to drugs ${ }^{2}$

\section{0,000}

Is the number of people the CSJ estimate would get addicted to cannabis ${ }^{3}$

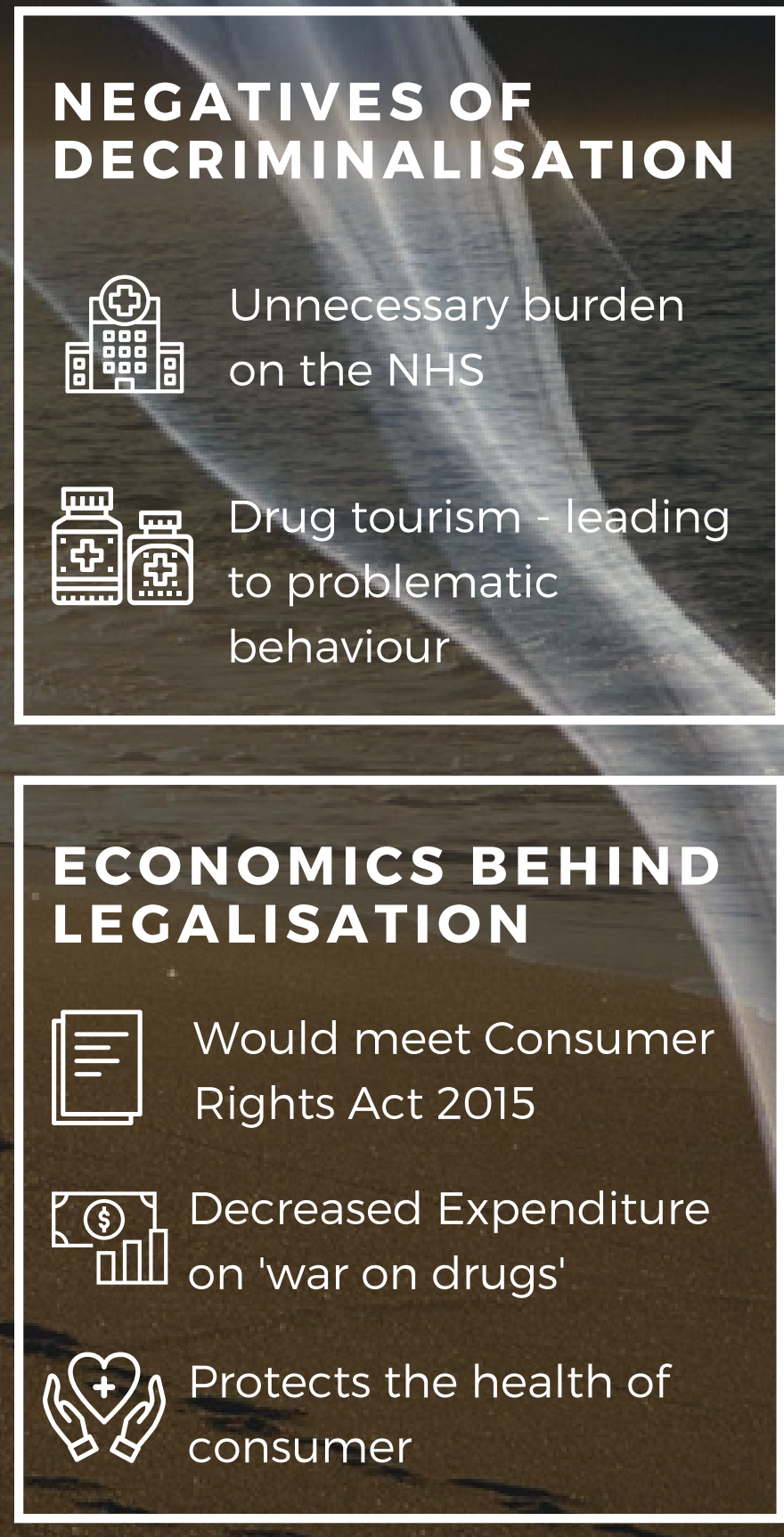

With the decriminalisation, and full legalisation of the drug trade, both the opportunity and profit motive for organised crime will diminish and the scope for trafficking and exploitation will reduce significantly.

By removing criminal penalties for drug possession, and focusing instead on facilitating access to support and treatment where it is needed, cycles of vulnerability can be cut off at the start.

"The supply of class A drugs, from urban hubs to county towns continues to be a widespread feature of gang activity and the key driver for the criminality highlighted"

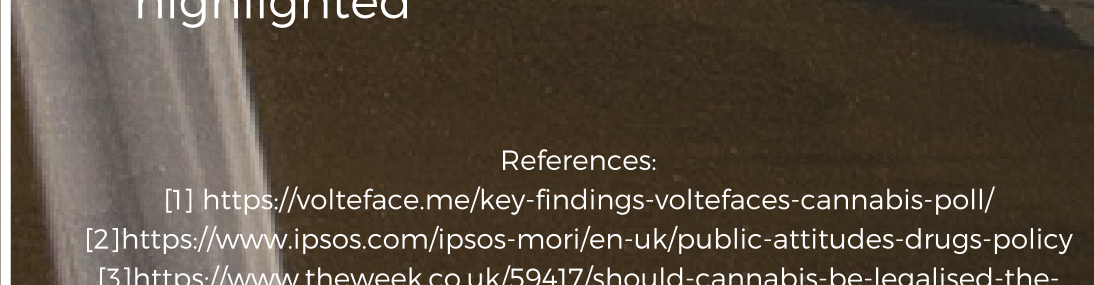
[3] https:///wnw. thess.com/ipsos-mori/en-uk/public-attitudes-drugs-policy pros-and-cons-of-decriminalising-drugs-general-election-2019 